\title{
Fluorescent Chromosome Banding and Genome Size Estimation in Three Species of Swertia
}

\author{
Myo Ma Ma Than ${ }^{1,2}$, Tapojita Samaddar ${ }^{1}$, \\ Biplab Kumar Bhowmick ${ }^{1,3}$ and Sumita Jha ${ }^{1 *}$
}

\author{
${ }^{1}$ CAS, Department of Botany, University of Calcutta, 35, Ballygunge Circular Road, Kolkata- 700019, India \\ ${ }^{2}$ TWOWS Post Doc. \& Senior Researcher, Network Activities Group, Mingalardon Orchid Garden, Yangon, \\ Myanmar \\ ${ }^{3}$ Department of Botany, Scottish Church College, 1 and 3, Urquhart Square, Kolkata-700006, India
}

Received June 23, 2017; accepted August 18, 2017

\begin{abstract}
Summary Chromosomal attributes of the critically endangered medicinal plant Swertia chirayita along with its allied species $S$. nervosa and $S$. bimaculata are precisely essential to assess phylogenetic relationships. The present study deals with karyomorphometric analysis based on patterns of fluorescence chromosome banding and nuclear genome size estimation by flow cytometry reported for the first time in $S$. chirayita $(2 n=26), S$. nervosa $(2 n=26)$ and $S$. bimaculata $(2 n=26)$. Fluorescent banding revealed the distinct differences in chromosomal $\mathrm{CMA}^{+\mathrm{ve}} / \mathrm{DAPI}^{-\mathrm{ve}}$ heterochromatic sites among the species. There were six chromosomes with $\mathrm{CMA}^{+\mathrm{ve}}$ signals in $S$. chirayita and two chromosomes with $\mathrm{CMA}^{+\mathrm{ve}}$ signals in $S$. bimaculata whereas all chromosomes of S. nervosa displayed $\mathrm{CMA}^{+\mathrm{ve}}$ signals. Due to a difference in CMA banding pattern, proportion of GC rich regions differed among the chromosomes of S. chirayita (3.32\%), S. nervosa (18.76\%), and S. bimaculata (0.64\%). S. bimaculata had the highest 2C DNA content $(9.82 \mathrm{pg} / 2 \mathrm{C})$ compared to $S$. nervosa $(1.95 \mathrm{pg} / 2 \mathrm{C})$ and $S$. chirayita $(1.09 \mathrm{pg} / 2 \mathrm{C})$. Lowest amount of GC-rich CMA sites along with highest DNA content distinguished $S$. bimaculata from the other two species. A nearly nine-fold difference in nuclear genome size among the homoploid species of Swertia $(2 n=26)$ and particular chromosomal discrimination by localized CMA bands allowed interpretation of karyotypic affiliations in the three species of Swertia.
\end{abstract}

Key words Swertia, Nuclear DNA content, Flow cytometry, Fluorochrome banding, Total chromatin length.

The genus Swertia L. (family Gentianaceae) occurs mainly in the temperate regions of the northern hemisphere. According to the Regionalization of World Flora by Takhtajan (1978), Swertia is said to be present in 14 regions of the world, with the highest species diversity in the Himalayas and South-Western China (Meusel et al. 1978). About 40 species of Swertia are found in India, distributed in the temperate Himalayan region (from Kashmir to Bhutan and also in the Khasia hills and Western Ghats). They are mainly found at high altitudes ranging from 1200 to $3000 \mathrm{~m}$ (Hooker 1885, Kirtikar and Basu 1984, Samaddar et al. 2014). The North West Himalayas are known to be the abode of 16 species of Swertia (Chopra et al. 1956, Garg 1987, Ho et al. 1994, Misra et al. 2010) and 13 species have been reported from the North Eastern states of India (Pradhan and Badola 2010, Samaddar et al. 2014).

Among the species of Swertia that are found in India, many have been described in different traditional systems of medicine, for their use in the treatment of various ailments (Kirtikar and Basu 1984, Misra et al. 2010). Of these species, Swertia chirayita is considered

\footnotetext{
*Corresponding author, e-mail: sumitajha.cu@gmail.com DOI: $10.1508 /$ cytologia. 82.513
}

to be of high medicinal value owing to its hypoglycemic and antimalarial activities (Brahmachari et al. 2004). It is designated as critically endangered owing to excessive human exploitation (Rai et al. 2000), resulting in the use of substitutes/adulterants in "chirata" trade. S. nervosa and S. bimaculata are among the popularly used substitutes of $S$. chirayita in the herbal industry (Joshi and Dhawan 2007). Growing demand in commercial trade and destructive harvesting beyond sustainable limits have already changed the IUCN status of many Swertia species. Germplasm documentation, preservation and genetic characterization thus have become essential for medicinal plants like Swertia (Samaddar et al. 2014).

The species of Swertia are taxonomically disputed owing to some overlapping macromorphological characters. S. chirayita, S. nervosa, and S. bimaculata show similarities in certain morphological characters like opposite decussate arrangement of leaves, inflorescence panicles of cymes, and loculicidal capsule type of fruits. However, distinctive differences such as nature of stem, leaf morphology, and floral features, have been helpful to discriminate the species (Hooker 1885, Rijal 2009, Samaddar et al. 2014, 2015). Molecular markers such as AFLP and RAPD have been employed for identification of the species of Swertia (Misra et al. 2010, Samad- 
dar et al. 2015). In terms of biochemical constituents, content of Swertiamerin was found to differ among $S$. chirayita, S. bimaculata, and $S$. nervosa (Samaddar et al. 2013). Amarogentin was found in S. chirayita and $S$. nervosa but not detected at all in S. bimaculata. The content of magniferin was also shown to be different in S. chirayita and $S$. nervosa (Khanal et al. 2015).

Being identified as a highly heterogeneous and polyphyletic genus (Chassot et al. 2001), chromosome study is considered to have great potential in evaluation of taxonomic affinities and phylogenetic relationships. There are only limited reports on chromosome analysis on Indian Swertia species (Khoshoo and Tandon 1963, Roy et al. 1988). We have recently reported chromosome number, karyotype, and meiotic analysis in Swertia species from Eastern Himalayas following conventional staining techniques (Samaddar et al. 2015). Based on conventional methods, $S$. chirayita and $S$. nervosa revealed an overall similarity in chromosome features while S. bimaculata had some differences in chromosome size and karyotype. There are many scopes to investigate chromosomal physiognomy based on advanced cytogenetic methods and fluorochrome banding analysis (Bhowmick et al. 2012, Jha and Yamamoto 2012, Nath et al. 2015). Especially the implication of enzymatic maceration and air drying technique (EMA, Fukui 1996) can potentially aid karyotype analysis following fluorochrome staining of chromosomes. In addition to chromosome analysis, interspecific genome size variation is considered as a taxonomically informative marker for homoploid species (Kron et al. 2007) which has not been reported so far in the case of Swertia. The use of flow cytometric methods for estimation of genome size has been recognized as a progressive measure to assess interspecific relationships (Bennett and Leitch 1995) which is aimed to improve cytogenetic background of the three species of Swertia. In the present study, nuclear DNA content and karyotype analysis based on fluorescence chromosome banding have been reported for the first time in the critically endangered species $S$. chirayita, $S$. nervosa, and $S$. bimaculata, to explore patterns of karyoevolutionary trends within the genus.

Materials and methods

\section{Plant materials}

Swertia chirayita (Roxb.) H. Karst. (synonym: Swertia chirata Buch.-Ham. ex Wall), Swertia nervosa (Wall. ex G. Don) C. B. Clarke and Swertia bimaculata (Sieb. \& Zucc.) Hook. f. \& Thomson ex C. B. Clarke plants with flowers and green fruits were collected during the month of September-November from Lava, Darjeeling, India. Collected specimens were identified on the basis of morphological characters and herbarium specimens were prepared. The voucher specimens have been deposited in the Herbarium of Shivaji University,
Kolhapur, (SUK) Maharashtra, India with the accession numbers SUK-5286, SUK-5288, and SUK-5287 for $S$. chirayita, S. nervosa, and S. bimaculata, respectively.

Seeds of each species were surface sterilized with $0.1 \% \mathrm{HgCl}_{2}(\mathrm{w} / \mathrm{v})$ for $30 \mathrm{~min}$, washed five times with sterilized distilled water and cultured on Murashige and Skoog's (1962) basal medium under $16 \mathrm{~h}$ photoperiod at $24^{\circ} \mathrm{C}$ and $60 \%$ relative humidity in a growth chamber. The roots and leaves obtained from in vitro derived plantlets were used for cytological study.

\section{Chromosome preparation for fluorochrome staining}

Healthy root tips $(0.5-1 \mathrm{~cm})$ obtained from two months old axenic seedlings were pretreated in 8-Hydroxyquinoline $(2 \mathrm{mM})$ at $20-22^{\circ} \mathrm{C}$ for $3.5 \mathrm{~h}$, fixed overnight in 1:3 glacial acetic acid:methanol and stored at $-20^{\circ} \mathrm{C}$. Fixed root tips were washed in cold distilled water and then incubated in enzyme mixture containing 1\% cellulose (Onozuka RS, Yakult Pharmaceutical Ind. Co., Ltd., Japan), 0.75\% macerozyme R-10 (Yakult Pharmaceutical Ind. Co., Ltd., Japan), 0.15\% pectolyase Y-23 (Kyowa Chemical Products Co., Ltd., Japan) and $1 \mathrm{mM}$ EDTA (pH 4.2) for 60 min (Fukui 1996). Enzyme digested root tips were macerated in a drop of fixative (1:3 aceto-methanol) on glass slides and air dried. Slides were stained with 2\% Giemsa solution (Giemsa azure eosine methylene blue solution, Merck, Germany) in $1 / 15$ phosphate buffer for $15 \mathrm{~min}$, rinsed with distilled water, air dried and mounted with xylene. Position of the metaphase plates were marked on slides and photographed using ProgRes ${ }^{\circledR}$ CT5 (Jenoptik, Germany) camera attached to Leitz GMBH microscope. Chromosome measurements [long arm length $(l)$, short arm length $(s)$, chromosome length (CL)] and total diploid chromatin length $\left(T C L=\sum_{i=1}^{2 n} C L\right)$ were taken using the software ProgRes 2.3.3. For karyotype analysis, chromosomes were classified on the basis of centromeric indices $[C i=(s / C L) \times 100]$ according to Levan et al. (1964) and designated as metacentric (M) (Ci>47.5-50.0), nearly metacentric (m) (Ci>37.5-47.5), submetacentric (sm) (Ci>25.0-37.5) and subtelocentric (st) $(C i>12.5-25.0)$. Chromosome morphometric data were taken from at least five different metaphase plates from three individual plants of each species to construct karyotypes.

Giemsa stained slides were destained in $70 \%$ methanol for subsequent staining of chromosomes with basespecific fluorochromes 4'-6-diamidino-2-phenylindole (DAPI) (AT-specific) and chromomycin $\mathrm{A}_{3}$ (CMA) (GCspecific), following the protocol of Schweizer (1976) with minor modifications (Bhowmick et al. 2012, Jha and Yamamoto 2012, Nath et al. 2015). Chromosomes were stained with $50 \mu \mathrm{g} \mathrm{mL}^{-1}$ DAPI solution with Actinomycin D as a counterstain and observed under fluorescent microscope Zeiss Axioscop 2 with a UV filter cassette. After observation, the same slides were stained 

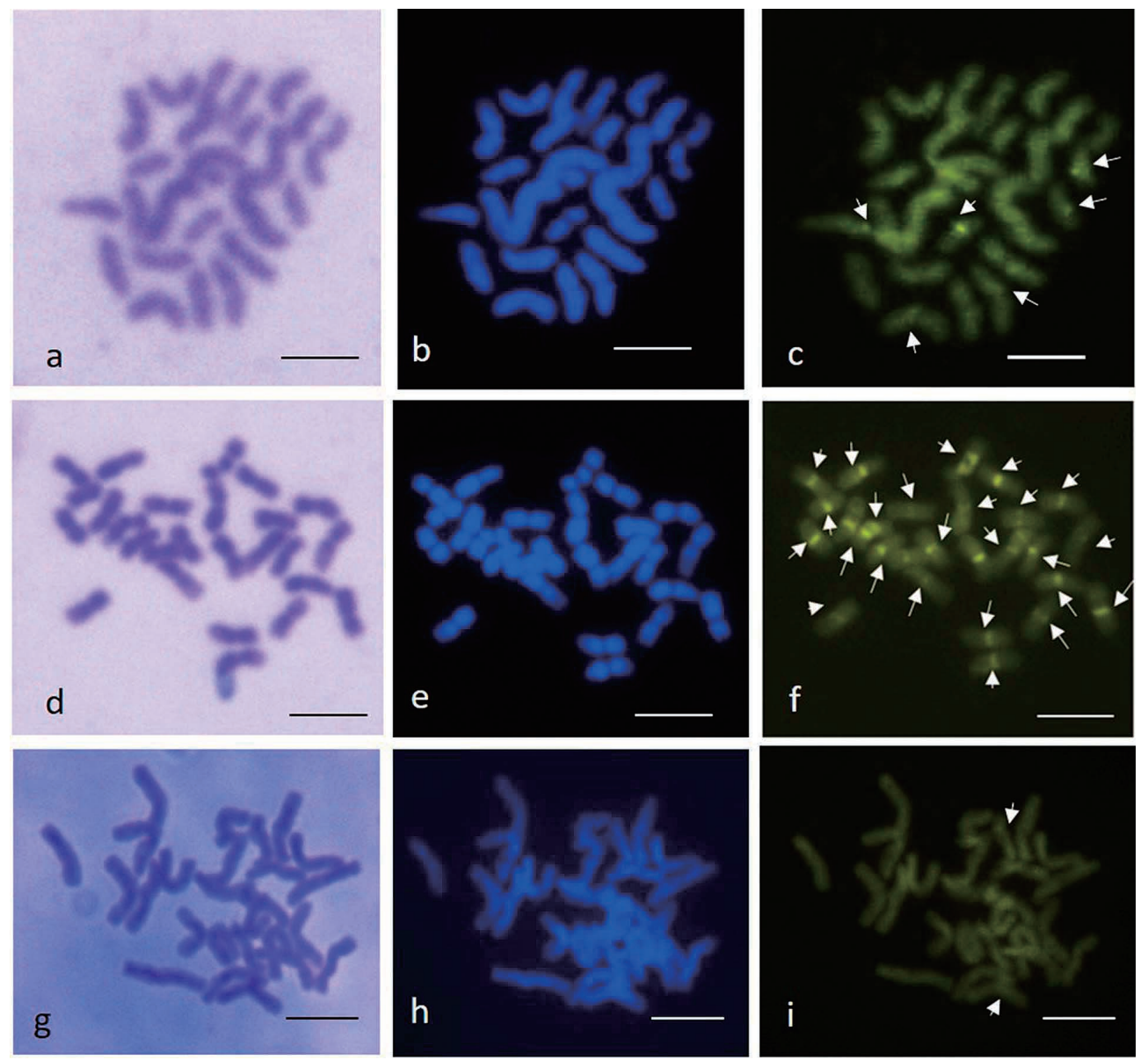

Fig. 1. Somatic metaphase chromosomes $(2 n=26)$ in the species of Swertia. $(\mathbf{a}-\mathbf{c})$ Chromosomes of Swertia chirayita stained with Giemsa (a), DAPI (b) and CMA3(c). (d-i) Chromosomes of Swertia nervosa stained with Giemsa (d), DAPI (e) and CMA3 (f). (g-i) Chromosomes of Swertia bimaculata stained with Giemsa (g), DAPI (h) and CMA3 (i). Arrows indicate $\mathrm{CMA}^{+\mathrm{ve}}$ signals on chromosomes. Bar scale $=10 \mu \mathrm{m}$.

with $0.1 \mathrm{mg} \mathrm{mL}^{-1} \mathrm{CMA}$ solution and observed under BV filter cassette. Images were captured with the camera ProgRes MFscan (Jenoptik, Germany) attached to Zeiss Axioscop2. Lengths of chromosomal fluorescent signals were measured using the software ProgRes CapturePro2.8.8. Based on the number and length of the signals, the GC rich regions in chromosomes was expressed as the relative percentage of total chromatin length (Moscone et al. 1996, Guerra 2000) for each species.

\section{Genome size estimation}

Leaves from two months old axenic seedling derived plants of S. chirayita, S. nervosa, and S. bimaculata were used as source material for nuclei isolation and estimation of genome size. The standard Zea mays L. 'CE-777' and Solanum lycopersicum L. 'Stupické polní rané' were kindly provided by Dr. Jaroslav Doležel, Institute of Experimental Botany, Olomouc, Czech Republic, with reported $2 \mathrm{C}$ value of 5.43 and $1.96 \mathrm{pg}$, respectively (Doležel et al. 2007). Nuclei isolation was done according to the protocol of Galbraith et al. (1983) in Tris- $\mathrm{MgCl}_{2}$ buffer (Pfosser et al. 1995) with $50 \mu \mathrm{g} \mathrm{mL}^{-1}$ RNase A. Leaves of standard and sample materials were co-chopped on ice beds with a sharp razor blade in a petridish, cell debris were precipitated by centrifugation and isolated nuclei were stained with propidium iodide (PI) $\left(50 \mu \mathrm{g} \mathrm{mL}^{-1}\right)$. Nuclei suspensions of sample and standard material were simultaneously analyzed using a BD FACS Verse Flow Cytometer (BD Bioscience, U.S.A.) with a $488 \mathrm{~nm}$ solid state laser $(50 \mathrm{~mW})$. Samples were run at a medium speed $\left(60 \mu \mathrm{L} \mathrm{min}^{-1}\right)$ and data were acquired and analyzed using the BD FACS Suite Software. A linear PI fluorescence Area (PI-A) vs. PI fluorescence Width (PI-W) plot was drawn to eliminate debris using qualitative gating. A PI fluorescence histogram (PI-A) was drawn to view nuclear DNA content. At least 3000 nuclei were run per sample and three replicates from three separate individuals were analyzed. Conversion of mass value into base-pair numbers was done according to the factor $1 \mathrm{pg}=978 \mathrm{Mbp}$ (Doležel et al. 2003).

\section{Statistical analysis}

Descriptive statistics were calculated and parameter studied included mean, standard deviation (SD) and minimum and maximum values. Results were expressed as mean and the Tukey's HSD test was used for post- 
hoc analyses. The statistical analysis was conducted at 95\% confidence level and $p$ value less than 0.05 was considered statistically significant. Principal component analysis (Marghali et al. 2014) was conducted to see cytological relationships between the three species of Swertia. The variables used for this study included quantitative data like the estimated total chromatin lengths, amount of $\mathrm{GC}$ rich regions in chromosomes as measured from the length of $\mathrm{CMA}^{+\mathrm{ve}}$ signals (Moscone et al. 1996, Guerra 2000) and 2C DNA content. InfoStat Version 2013d (free version) was used for correlation analysis using the non-parametric Spearman test (Sokal and Rohlf 1995) and principal component analysis.

\section{Results}

Karyomorphological analysis based on fluorescent banding pattern

The number of chromosomes in the diploid complement was $2 n=26$. EMA-Giemsa method facilitated elimination of cytoplasmic background and clear visualization of chromosome morphology in the species of Swertia (Fig. 1). S. chirayita $(2 n=26)$ and $S$. nervosa $(2 n=26)$ are characterized by the presence of small chromosomes $(\leq 3.5 \mu \mathrm{m})$ while most of the chromosomes in S. bimaculata $(2 n=26)$ are of medium size $(3.5-6 \mu \mathrm{m})$.
The total chromatin length was found to display significant differences between $S$. bimaculata and $S$. chirayita while $S$. nervosa had a TCL of intermediate value (Table 1). Somatic metaphase complement of the three species of Swertia displayed distinct karyomorphology and all had a pair of chromosomes with two constrictions (Table $1)$.

Fluorescence banding of the EMA-Giemsa stained metaphase plates enabled clarification of chromosomal differences among the species of Swertia. Chromosomes stained with DAPI did not display any specific bands while a differential distribution of $\mathrm{CMA}^{+\mathrm{ve}}$ signals was evident among the species (Figs. 1, 2). The $\mathrm{CMA}^{+\mathrm{ve}}$ signals always corresponded with $\mathrm{DAPI}^{-\mathrm{ve}}$ areas on the chromosomes. On the basis of position and number of chromosomal $\mathrm{CMA}^{+\mathrm{ve}}$ signals, six types of chromosomes were categorized which are differentially distributed in the three species of Swertia. The $\mathrm{CMA}^{+\mathrm{ve}}$ signals always corresponded with $\mathrm{DAPI}^{-\mathrm{ve}}$ areas on the chromosomes. Chromosomes with $\mathrm{CMA}^{+\mathrm{ve}}$ signals at the centromeric region were designated as type A, chromosomes with proximal $\mathrm{CMA}^{+\mathrm{ve}}$ signals were designated as type $\mathrm{B}$, chromosomes with $\mathrm{CMA}^{+\mathrm{ve}}$ signals at centromeric and interstitial region on long arm was termed type $\mathrm{C}$, nucleolar chromosomes with one $\mathrm{CMA}^{+\mathrm{ve}}$ signal at the nucleolar constriction were designated type $\mathrm{D}$, nu-

a
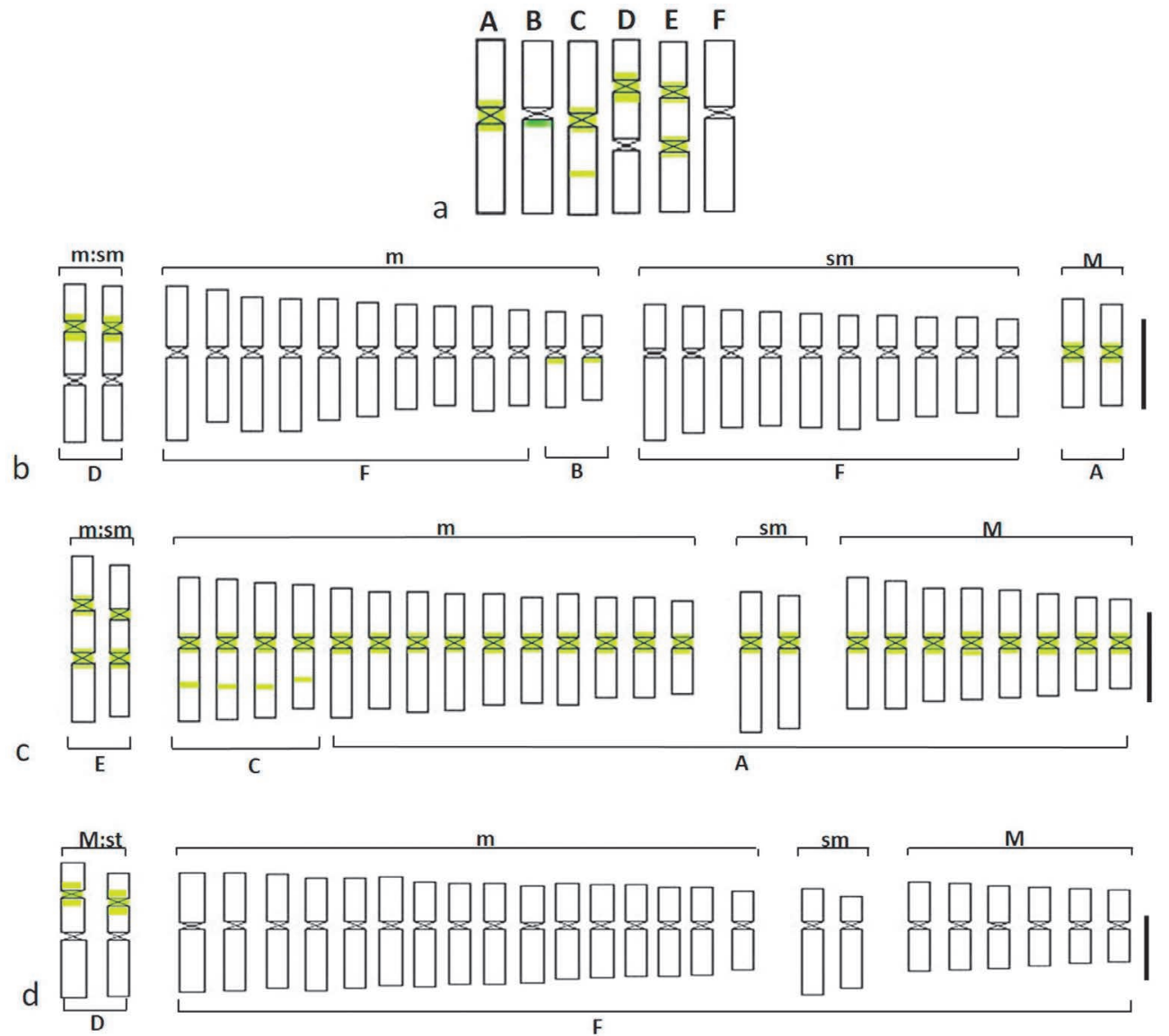

Fig. 2. (a) Chromosome types of Swertia species based on $\mathrm{CMA}^{+\mathrm{ve}}$ signals. Ideograms of $S$. chirayita (b), S. nervosa (c) and $S$. bimaculata $(\mathbf{d})$, chromosomes arranged according to descending length. Bar scale $=1 \mu \mathrm{m}$. 
Table 1. Comparative karyomorphology based on fluorescent banding and nuclear DNA content of three species of Swertia.

\begin{tabular}{|c|c|c|c|c|c|c|c|}
\hline \multirow{2}{*}{ Species } & \multirow{2}{*}{ Karyotype } & \multicolumn{2}{|c|}{ Nuclear DNA content } & \multirow{2}{*}{$\mathrm{TCL}(\mu \mathrm{m})$} & \multirow{2}{*}{$\begin{array}{c}\text { No. of } \\
\text { chromosomes with } \\
\text { CMA }^{+v e} \text { signals }\end{array}$} & \multirow{2}{*}{$\begin{array}{c}\text { Karyotype on the basis } \\
\text { of } \mathrm{CMA}^{+\mathrm{ve}} \text { banding } \\
\text { pattern }\end{array}$} & \multirow{2}{*}{$\begin{array}{l}\text { Chromosomal GC } \\
\text { rich regions } \\
\left(\mathrm{CMA}^{+\mathrm{ve}}\right)\end{array}$} \\
\hline & & $\mathrm{pg} / 2 \mathrm{C}$ & $\mathrm{Mbp} / 2 \mathrm{C}$ & & & & \\
\hline S. chirayita $(2 n=26)$ & $2 \mathrm{M}+12 \mathrm{~m}+10 \mathrm{sm}+2 \mathrm{~m}: \mathrm{sm}$ & $1.09 \pm 0.16^{\mathrm{a}}$ & $1062.76 \pm 152.87^{\mathrm{a}}$ & $60.14 \pm 4.97^{\mathrm{a}}$ & 6 & $2 \mathrm{~A}+2 \mathrm{~B}+2 \mathrm{D}+20 \mathrm{~F}$ & $3.32 \pm 0.21^{\mathrm{a}}$ \\
\hline S. nervosa $(2 n=26)$ & $8 \mathrm{M}+14 \mathrm{~m}+2 \mathrm{sm}+2 \mathrm{~m}: \mathrm{sm}$ & $1.95 \pm 0.14^{\mathrm{a}}$ & $1910.36 \pm 137.04^{\mathrm{a}}$ & $80.27 \pm 1.71^{\mathrm{b}}$ & 26 & $20 \mathrm{~A}+4 \mathrm{C}+2 \mathrm{E}$ & $18.76 \pm 2.51^{\mathrm{b}}$ \\
\hline S. bimaculata $(2 n=26)$ & $6 \mathrm{M}+16 \mathrm{~m}+2 \mathrm{sm}+2 \mathrm{M}: \mathrm{st}$ & $9.82 \pm 0.71^{\mathrm{b}}$ & $9607.22 \pm 691.30^{\mathrm{b}}$ & $133.16 \pm 13.03^{b}$ & 2 & $2 \mathrm{D}+24 \mathrm{~F}$ & $0.64 \pm 0.20^{\mathrm{c}}$ \\
\hline
\end{tabular}

Values followed by same letter are not significantly different according to Tukey's HSD test ( $p=0.05)$. TCL: total diploid chromosome length.
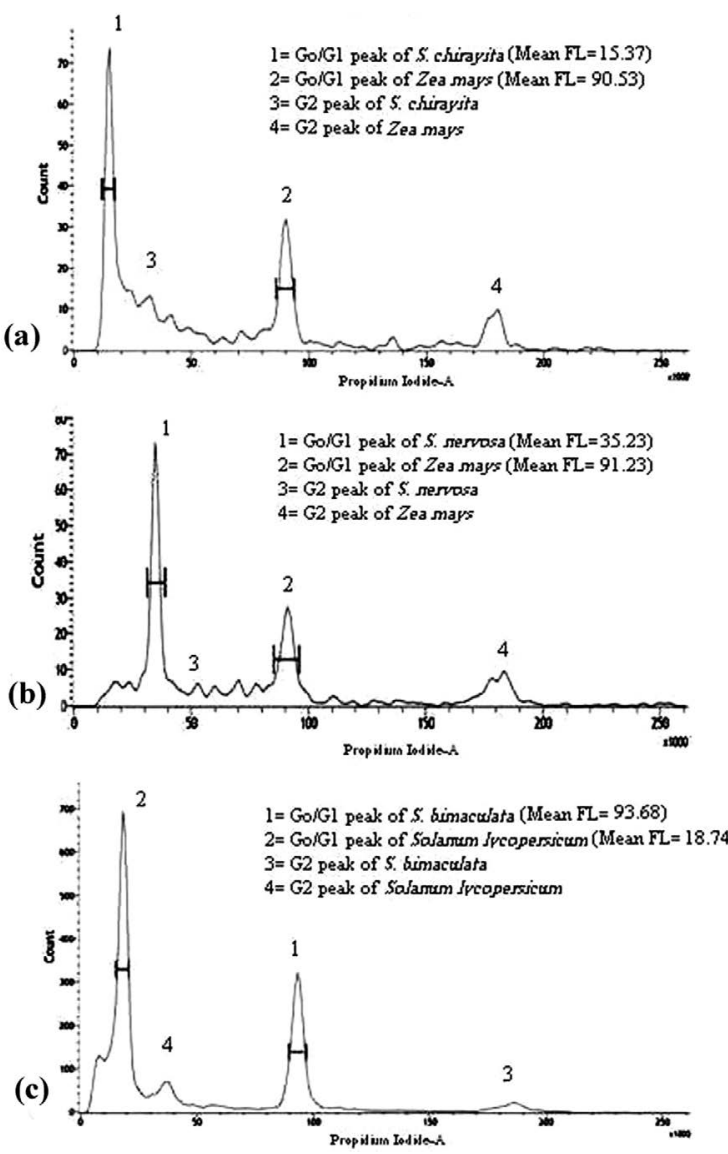

Fig. 3. Propidium iodide fluorescence intensity-area (PI-A) histograms of Swertia chirayita (a) and Swertia nervosa (b) with internal standard Zea mays L. 'CE-777.' (c) Propidium iodide fluorescence intensity-area (PI-A) histograms of Swertia bimaculata with internal standard Solanum lycopersicum L. 'Stupické polní rané. Mean FL=Mean fluorescence intensity.

cleolar chromosomes with $\mathrm{CMA}^{+\mathrm{ve}}$ signal at centromeric as well as the nucleolar constriction were designated type E, and chromosomes with no detectable CMA signals were type $\mathrm{F}$ (Fig. 2a).

In $S$. chirayita, one pair of metacentric chromosomes had centromeric $\mathrm{CMA}^{+\mathrm{v} e}$ signals (type A). Another pair of nearly metacentric chromosomes had proximal $\mathrm{CMA}^{+\mathrm{ve}}$ signal on the long arm (type B). One pair of chromosomes with two constrictions (m.sm) showed the presence of $\mathrm{CMA}^{+\mathrm{ve}}$ signal on the submedian constriction (type D) (Fig. 1a-c, Fig. 2b). Ten pairs of chromosomes did not possess any $\mathrm{CMA}^{+\mathrm{ve}}$ signals (type F). Hence the karyotype of $S$. chirayita according to CMA banding pattern was $2 \mathrm{~A}(2 \mathrm{M})+2 \mathrm{~B}(2 \mathrm{~m})+2 \mathrm{D}(2 \mathrm{~m} \cdot \mathrm{sm})+20 \mathrm{~F}$
$(10 \mathrm{~m}+10 \mathrm{sm})$ (Fig. 2b, Table 1).

In the case of $S$. nervosa, $\mathrm{CMA}^{+\mathrm{ve}}$ signals were observed in all somatic chromosomes (Fig. 1d-f). Centromeric $\mathrm{CMA}^{+\mathrm{ve}}$ signals (type A) were found in 20 chromosomes of which 8 were metacentric, 10 were nearly metacentric, and 2 were submetacentric. There were four nearly metacentric chromosomes with $\mathrm{CMA}^{+\mathrm{ve}}$ signals at centromeric and interstitial region (type $C$ ). In the case of the nucleolar pair of chromosomes of $S$. nervosa, $\mathrm{CMA}^{+\mathrm{ve}}$ signals were detected at both the nearly median and submedian constrictions (type E). Thus, on the basis of CMA banding pattern, the karyotype of $S$. nervosa was $20 \mathrm{~A}(8 \mathrm{M}+10 \mathrm{~m}+2 \mathrm{sm})+4 \mathrm{C}(4 \mathrm{~m})+2 \mathrm{E}(\mathrm{m} . \mathrm{sm})$ (Fig. 2c, Table 1).

$\mathrm{CMA}^{+\mathrm{ve}}$ signals were observed only at the subterminal constriction of the nucleolar pair of $S$. bimaculata (type B1). The rest of the chromosomes did not possess any $\mathrm{CMA}^{+\mathrm{ve}}$ signals and belong to Type $\mathrm{F}$ (Fig. 1g-i, Fig. 2d). Thus, on the basis of $\mathrm{CMA}^{+\mathrm{ve}}$ banding pattern the karyotype of $S$. bimaculata is $2 \mathrm{D}$ (M:st)+ $24 \mathrm{~F}(6 \mathrm{M}+16 \mathrm{~m}+2 \mathrm{sm})$.

Based on the presence of chromosomal CMA signals, the GC rich elements in the species of Swertia exhibited differential distribution (Table 1). The proportion of $\mathrm{GC}$ rich regions was highest in the chromosomes of $S$. nervosa $(18.76 \%)$ followed by that of $S$. chirayita $(3.32 \%)$ while lowest $\mathrm{GC}$ rich chromosomal region was found in S. bimaculata $(0.64 \%)$ (Table 1).

Genome size of $\mathrm{S}$. chirayita, S. nervosa, and $\mathrm{S}$. bimaculata

Comparison of $2 \mathrm{C}$ values revealed interspecific difference in DNA contents which reached up to about nine fold in the case of Swertia bimaculata. The highest nuclear DNA content of $9.82 \mathrm{pg} / 2 \mathrm{C}$ was observed in $S$. bimaculata and was significantly different from that of the other two species: $S$. nervosa $(1.95 \mathrm{pg} / 2 \mathrm{C})$ and $S$. chirayita (1.09pg/2C) (Table 1, Fig. 3). Nuclear DNA content was positively correlated with TCL $(r=1.00$, $p=0.16$ ).

Interspecific chromosomal relationship based on principal component analysis

Principal component analysis revealed the formation of three distinct locations for S. chirayita, S. nervosa, and S. bimaculata (Fig. S1) in PCA plot. S. chirayita and $S$. nervosa were relatively close in terms of the karyo- 
type variables while $S$. bimaculata noticeably occupied a distant position than these two species (PC1 17.0\% and PC2 $83.0 \%$ values). Distant location of S. bimaculata indicated significant differences from $S$. chirayita and $S$. nervosa.

\section{Discussion}

The chromosome number $(2 n=26)$ and karyotypes studied in the Swertia species, corroborated to a previous report of conventional acetoorcein based study (Samaddar et al. 2015). Fluorochrome banding and genome size estimation in the critically endangered species $S$. chirayita and its adulterant species $S$. nervosa and $S$. bimaculata enabled cytological characterization of three species showing distinct differences within the genus. Nuclear DNA content of the Swertia species positively correlated with TCL $(r=1.00, p=0.16)$ which is a general trend in plants (Acosta et al. 2012). In spite of being a homoploid species, S. bimaculata has significantly higher length of total chromatin and nuclear DNA content than $S$. chirayita and $S$. nervosa and hence can be distinguished based on 2C DNA values. Such a difference in nuclear DNA content between homoploids indicates taxonomic heterogeneity in rapidly diverging species (Loureiro et al. 2010). Especially, the remarkable divergence in genome size of $S$. bimaculata without any change in chromosome number had exceeded genome size divergence in many other homoploid species (Loureiro et al. 2010). Apart from the difference in 2C DNA content, unique fluorochrome banding pattern enabled cytological distinction between these species.

Previously, karyotype differences between species was accomplished after a thorough analysis of chromosome morphometric parameters based on conventional acetoorcein staining (Samaddar et al. 2015). In the current study, staining of the somatic chromosomes with chromomycin A3 clarified species identification at a single glance (Fig. 1) based on presence and absence of CMA bands and mode of distribution of CMA signals. EMA method had been central in the implication of fluorochrome banding technique since the method results in well spread metaphase chromosomes with representable morphology (Fig. 1). S. nervosa exhibited the greatest preponderance of $\mathrm{GC}$ rich $\mathrm{CMA}^{+\mathrm{ve}}$ signals on the chromosomes. The physical positioning of $\mathrm{GC}$ rich bands in $S$. nervosa appeared in the centromeric regions in all chromosomes, corresponding to an equilocal pattern of distribution (Fig. 1d-f, Fig. 2c). Although uncommon, centromeric occurrence of $\mathrm{GC}$ rich $\mathrm{CMA}^{+\mathrm{ve}}$ sites were previously detected in the chromosomes of Coccinia grandis (Bhowmick et al. 2012). The occurrence of $\mathrm{CMA}^{+\mathrm{ve}}$ signals on nucleolar constrictions perhaps constitutes the NOR- GC elements in S. nervosa like in many other plant species (Guerra 2000). Apart from the centromeric and nucleolar regions, interstitial
GC rich blocks are also found in two pairs of chromosomes remaining as a distinctive chromosomal marker for S. nervosa (Fig. 2c). Although CMA-positive signals commonly represent GC-rich heterochromatin (Guerra 2000), the exact nature and function of the GC rich $\mathrm{CMA}^{+\mathrm{ve}}$ sites is subject to further characterization.

In the case of $S$. chirayita, centromeric $\mathrm{CMA}^{+\mathrm{ve}}$ signals were detected in one pair. Another pair of chromosomes had proximal $\mathrm{CMA}^{+\mathrm{ve}}$ site just below centromere. The nucleolar pair had $\mathrm{CMA}^{+\mathrm{ve}}$ signals only at the nucleolar constriction (Fig. 2b). However, the proportion of GC rich sites in $S$. chirayita was considerably low compared to the adulterant species, $S$. nervosa. The pair of nucleolar chromosomes that have been reported to be alike in $S$. chirayita and $S$. nervosa, could be distinguished by CMA banding patterns as type D in the former and type $\mathrm{E}$ in the latter species.

It is interesting to note that $S$. bimaculata with largest TCL and genome size had the lowest heterochromatin $(0.64 \%)$ among the three species. The nucleolar constriction had a CMA signal of type D (Fig. 2d) and rest of the chromosomes had a uniform pattern of CMA staining. The reduction in chromosomal CMA signals might result from dispersed nature of $\mathrm{GC}$ rich sequences in the genome. A correlation between the largest genome size in S. bimaculata and the very limited amount of GC rich $\mathrm{CMA}^{+\mathrm{ve}}$ sites remains to be a stimulating concern. Moscone et al. (2003) suggested that the increase in repetitive sequences not only at particular chromosomal sites but also at dispersed locations can lead to expansion in genome size as found in Capsicum which may be plausible also in Swertia bimaculata.

Presently, a combination of cytological features such as karyotype, fluorochrome banding pattern, and nuclear genome size had been employed to assess interspecific relationships by PCA. Distinct positions of the three species in a PCA plot indicated the utility of the present approach for cytological characterization of each species. A relative proximity between $S$. chirayita and $S$. nervosa probably indicates karyotype affinity as was reported earlier (Samaddar et al. 2015). However, S. bimaculata was found to have profound divergence in terms of chromosomal features and DNA content as evident after principal component analysis (Fig. S1).

Our study is the first report on fluorochrome banding pattern and genome size estimation in the genus Swertia. The current study provides reference for further evaluation of other Swertia species to understand the trend of chromosomal GC-rich element distribution in relation to nuclear DNA contents in the genus. Such molecular cytogenetic analysis can furnish valuable information to consolidate the existing knowledge on the evolution and systematics of the group and can be used as a platform for further studies. 


\section{Acknowledgements}

MMMT thanks the Department of Biotechnology, Government of India and the Third World Organization for Women in Science, TWOWS, Italy for the award of DBT-TWOWS Post Doctoral Fellowship and Ms. Sayantani Nath for technical help. TS acknowledges the University Grants Commission (UGC, GOI) for the award of RFSMS Fellowship. The authors are grateful to Prof. Timir Baran Jha for his help and guidance in fluorescence banding technique. The authors thank Prof. Jaroslav Doležel, Institute of Experimental Botany, Olomouc, Czech Republic for the provision of seeds for reference standard. The authors thank the Head of the Department of Botany, and Programme Coordinator, CAS, Department of Botany, University of Calcutta for the facilities provided. Thanks is due to the Director, CU- BD CoE for Nanobiotechnology, CRNN, University of Calcutta for providing instrument facilities.

\section{References}

Acosta, M. C., Guerra, M. and Moscone, E. A. 2012. Karyological relationships among some South American species of Solanum (Solanaceae) based on fluorochrome banding and nuclear DNA amount. Plant Syst. Evol. 298: 1547-1556.

Bennett, M. D. and Leitch, I. J. 1995. Nuclear DNA amounts in angiosperms. Ann. Bot. 76: 113-176.

Bhowmick, B. K., Jha, T. B. and Jha, S. 2012. Chromosome analysis in the dioecious cucurbit Coccinia grandis (L.). Voigt. Chromosome Sci. 15: 9-15.

Brahmachari, G., Mondal, S., Gangopadhyay, A., Gorai, D., Mukhopadhyay, B., Saha, S. and Brahmachari, A. K. 2004. Swertia (Gentianaceae): chemical and pharmacological aspects. Chem. Biodivers. 1: 1627-1651.

Chassot, P., Nemomissa, S., Yuan, Y. M. and Küpfer, P. 2001. High paraphyly of Swertia L. (Gentianaceae) in the Gentianellalineage as revealed by nuclear and chloroplast DNA sequence variation. Plant Syst. Evol. 229: 1-21.

Chopra, R. N., Nayar, S. L., Chopra, I. C., Asolkar, L. V., Kakkar, K. K., Chakre, O. J. and Varma, B. S. 1956. Glossary of Indian Medicinal Plants. Council of Scientific \& Industrial Research, New Delhi.

Doležel, J., Bartoš, J., Voglmayr, H. and Greilhuber, J. 2003. Nuclear DNA content and genome size of trout and human. Cytometry A 51: 127-128, author reply 129 .

Doležel, J., Greilhuber, J. and Suda, J. 2007. Estimation of nuclear DNA content in plants using flow cytometry. Nat. Protoc. 2: 2233-2244.

Fukui, K. 1996. Plant chromosomes at mitosis. In: Fukui, K. and Nakayama, S. (eds.). Plant Chromosomes: Laboratory Methods. CRC Press Inc., Boca Raton. pp. 1-17.

Galbraith, D. W., Harkins, K. R., Maddox, J. M., Ayres, N. M., Sharma, D. P. and Firoozabady, E. 1983. Rapid flow cytometric analysis of the cell cycle in intact plant tissues. Science 220: 1049-1051.

Garg, S. 1987. Gentianaceae of the North West Himalaya (a revision). In: International Bioscience Monograph 17. Today and Tomorrow's Printers and Publishers, New Delhi.

Guerra, M. 2000. Patterns of heterochromatin distribution in plant chromosomes. Genet. Mol. Biol. 23: 1029-1041.

Ho, T. N., Xue, C. Y. and Wang, W. 1994. The origin, dispersal and formation of the distribution pattern of Swertia L. (Gentianaceae). J. Syst. Evol. 32: 525-537.

Hooker, J. D. 1885. The Flora of British India. L. Reeve and Co., London.

Jha, T. B. and Yamamoto, M. 2012. Application of EMA, fluorescent staining and FISH of rDNA in analysis of Aloe vera (L.) Burm. f. chromosomes. Bull. Fac. Agr. Kagoshima Univ. 62: 83-89.

Joshi, P. and Dhawan, V. 2007. Axillary multiplication of Swertia chirayita (Roxb. Ex Fleming) H. Karst., a critically endangered medicinal herb of temperate Himalayas. In Vitro Cell. Dev. Biol. Plant 43: 631-638.

Khanal, S., Shakya, N., Thapal, K. and Pant, D. R. 2015. Phytochemical investigation of crude methanol extracts of different species of Swertia from Nepal. BMC Res. Notes 8: 821.

Khoshoo, T. N. and Tandon, S. R. 1963. Cytological and pollination studies on some Himalayan species of Swertia. Caryologia 16: 445-477.

Kirtikar, K. R. and Basu, B. D. 1984. Indian Medicinal Plants, Allahabad III: $1664-1666$.

Kron, P., Suda, J. and Husband, B. C. 2007. Applications of flow cytometry to evolutionary and population biology. Annu. Rev. Ecol. Evol. Syst. 38: 847-876.

Levan, A., Fredga, K. and Sandberg, A. A. 1964. Nomenclature for centromeric position on chromosomes. Hereditas 52: 201-220.

Loureiro, J., Trávníček, P., Rauchová, J., Urfus, T., Vit, P., Stech, M., Castro, S. and Suda, J. 2010. The use of flow cytometry in the biosystematics, ecology and population biology of homoploid plants. Preslia 82: 3-21.

Marghali, S., Zitouna, N., Gharbi, M., Chennaoui-Kourda, H. and Trifi-Farah, N. 2014. Morphological and molecular characters: Congruence or conflict in the phylogeny of Sulla species? Aust. J. Crop Sci. 8: 148-158.

Meusel, H., Jäger, E., Rauschert, S. and Weinert, E. 1978. Vergleichende Chlorologie der Zentraleuropäischen Flora II (Karten). VEB Gustav Fischer Verlag, Jena, Germany.

Misra, A., Shasany, A. K., Shukla, A. K., Darokar, M. P., Singh, S. C., Sundaresan, V., Singh, J., Bagchi, G. D., Jain, S. P., Saikia, D. and Khanuja, S. P. 2010. AFLP markers for identification of Swertia species (Gentianaceae). Genet. Mol. Res. 9: 1535-1544.

Moscone, E. A., Baranyi, M., Ebert, I., Greilhuber, J., Ehrendorfer, F. and Hunziker, A. T. 2003. Analysis of nuclear DNA content in Capsicum (S. olanaceae) by flow cytometry and Feulgen densitometry. Ann. Bot. 92: 21-29.

Moscone, E. A., Lambrou, M. and Ehrendorfer, F. 1996. Fluorescent chromosome banding in the cultivated species of Capsicum (Solanaceae). Plant Syst. Evol. 202: 37-63.

Murashige, T. and Skoog, F. 1962. A revised medium for rapid growth and bio assays with tobacco tissue cultures. Physiol. Plant. 15: 473-497.

Nath, S., Jha, T. B., Mallick, S. K. and Jha, S. 2015. Karyological relationships in Indian species of Drimia based on fluorescent chromosome banding and nuclear DNA amount. Protoplasma 252: 283-299.

Pfosser, M., Amon, A., Lelley, T. and Heberle-Bors, E. 1995. Evaluation of sensitivity of flow cytometry in detecting aneuploidy in wheat using disomic and ditelosomic wheat-rye addition lines. Cytometry 21: 387-393.

Pradhan, B. K. and Badola, H. K. 2010. Chemical stimulation of seed germination in ex situ produced seeds in Swertia chirayita, a critically endangered medicinal herb. Res. J. Seed Sci. 3: 139-149.

Rai, L. K., Prasad, P. and Sharma, E. 2000. Conservation threats to some medicinal plants of the Sikkim Himalaya. Biol. Conserv. 93: $27-33$.

Rijal, D. P. 2009. Taxonomic study of some medicinally important species of Swertia L. (Gentianaceae) in Nepal. Bot. Orient. J. 
Plant Sci. 6: 18-24.

Roy, S. C., Ghosh, S. and Chatterjee, A. 1988. A cytological survey of Eastern Himalayan plants II. Cell Chromosome Res. 11: 93-97.

Samaddar, T., Chaubey, B., Jha, S. and Jha, T. B. 2013. Determination of swertiamarin and amarogentin content and evaluation of antibacterial activity in Eastern Himalayan species of Swertia L. Phcog. Commn. 3: 64-70.

Samaddar, T., Jha, S. and Jha, T. B. 2014. Indian Swertia from Eastern Himalaya: strategies of conservation and biotechnological improvements. The Gentianaceae. Vol. 1-Characterization and Ecology. Springer-Verlag Berlin Heidelberg. pp. 279-301.
Samaddar, T., Than, M. M. M., Jha, T. B. and Jha, S. 2015. Cytogenetic and DNA fingerprinting analysis in three species of Swertia from Eastern Himalaya. Caryologia 68: 207-216.

Schweizer, D. 1976. Reverse fluorescent chromosome banding with chromomycin and DAPI. Chromosoma 58: 307-324.

Sokal, R. R. and Rohlf, F. J. 1995. Biometry: the principles and practice of statistics in biological research. W. H. Freeman \& Co., New York.

Takhtajan, A. L. 1978. The floristic regions of the world. Soviet Sciences Press, Moscow. 